\title{
Transmission Electron Microscopy (TEM) Studies on Nickel and Molybdenum Nitrides as Oxygen Reduction Reaction Catalysts
}

\author{
Yunzhi Liu ${ }^{1 *}$, Melissa E. Kreider ${ }^{2}$, Michaela Burke Stevens ${ }^{2}$, Laurie A. King ${ }^{2}$, Thomas F. Jaramillo ${ }^{2}$ and \\ Robert Sinclair ${ }^{1}$ \\ 1. Department of Materials Science and Engineering, Stanford University, Stanford, CA 94305, USA \\ 2. Department of Chemical Engineering, Stanford University, Stanford, CA 94305, USA \\ *Corresponding author: yunzhil@stanford.edu
}

As a promising technology towards efficiently producing electricity for transportation applications, proton-exchange membrane fuel cells (PEMFC) with platinum-based catalysts are limited by the high cost from deploying these precious metals. ${ }^{1}$ Developing active, stable and low-cost catalysts has thus become necessary for viable application of PEMFC. Among promising non-precious group catalytic materials for the oxygen reduction reaction (ORR), transition metal nitrides have attracted attention because of their activity and stability in acid electrolyte. ${ }^{2,3}$ In the present study, nickel nitride $\left(\mathrm{Ni}_{\mathrm{x}} \mathrm{N}\right)$ and molybdenum nitride $\left(\mathrm{Mo}_{\mathrm{x}} \mathrm{N}\right)$ thin films were prepared by reactive sputtering. These materials were found to be active, stable and selective to reactions, and the properties were found to be dependent on the catalyst structures.

Conventional cross-sectional TEM specimens were prepared to understand better the relationship between the activity and structure. High resolution (HR) TEM images and selected area diffraction patterns (SADP) were taken in a FEI Titan Environment TEM operated at $300 \mathrm{kV}$. As shown in Figure 1A, the crosssectional TEM image of the $\mathrm{Ni}_{\mathrm{x}} \mathrm{N}$ thin film has a pillar morphology. SADPs were used to determine the crystal structure at the surface and in the bulk shown in Figure $1 \mathrm{~B}, \mathrm{C}$ respectively. The positions of the SA aperture are marked in $1 \mathrm{~A}$. In Figure 1B, the SADP is showing a good match with the diffraction pattern of the $\mathrm{Ni}_{4} \mathrm{~N}$ cubic structure taken near the [233] zone axis. In Figure $1 \mathrm{C}$, the diffraction rings corresponding to $\mathrm{Ni}_{4} \mathrm{~N}$ (labeled in red) and $\mathrm{Ni}_{3} \mathrm{~N}$ (labeled in yellow) are showing up together indicating that the film is primarily composed of $\mathrm{Ni}_{4} \mathrm{~N}$, with a minor phase of $\mathrm{Ni}_{3} \mathrm{~N}$. The thin film is polycrystalline as seen from the SADP pattern in 1C and HR-TEM images shown in Figure 2.

The electrochemical failure mechanisms of $\mathrm{Mo}_{\mathrm{x}} \mathrm{N}$ thin films were confirmed through ex situ crosssectional TEM characterization. As seen from Figure 3A and 3B, the thin film has lost a significant amount of the material after an electrochemical test in acidic testing conditions (cyclic voltammograms in $0.1 \mathrm{M}$ $\mathrm{HClO}_{4}$ ). The bulk thin film is found to be polycrystalline according to the diffraction patterns in Figure 3C. The SADP is showing that the structure of these thin films fits a rocksalt structure with lattice constant of $0.419 \mathrm{~nm}$, which corresponds to $\mathrm{MoN}$ with the $\mathrm{NaCl}$ structure. In conclusion, the failure mechanism of this thin film was confirmed to be material loss in an acid environment rather than by a phase change by comparing the SADPs and bright-field (BF) TEM from both before and after test thin films.

This work shows the usefulness of TEM characterization to reveal changes in catalytic thin film structures after electrochemical testing in a harsh environment. ${ }^{[4]}$

References:

[1] A. Rabis, P. Rodriguez and T. J. Schmidt. Acs Catalysis 2.5 (2012): p. 864-890.

[2] B. Cao et al, Inorganic Chemistry 54.5 (2015): p.2128-2136.

[3] S. Dong et al, Coordination Chemistry Reviews 257.13-14 (2013), p.1946-1956. 
[4] Financial support from the Toyota Research Institute - Accelerated Materials Design and Discovery (TRI-AMDD) program (Stanford University) is much appreciated.
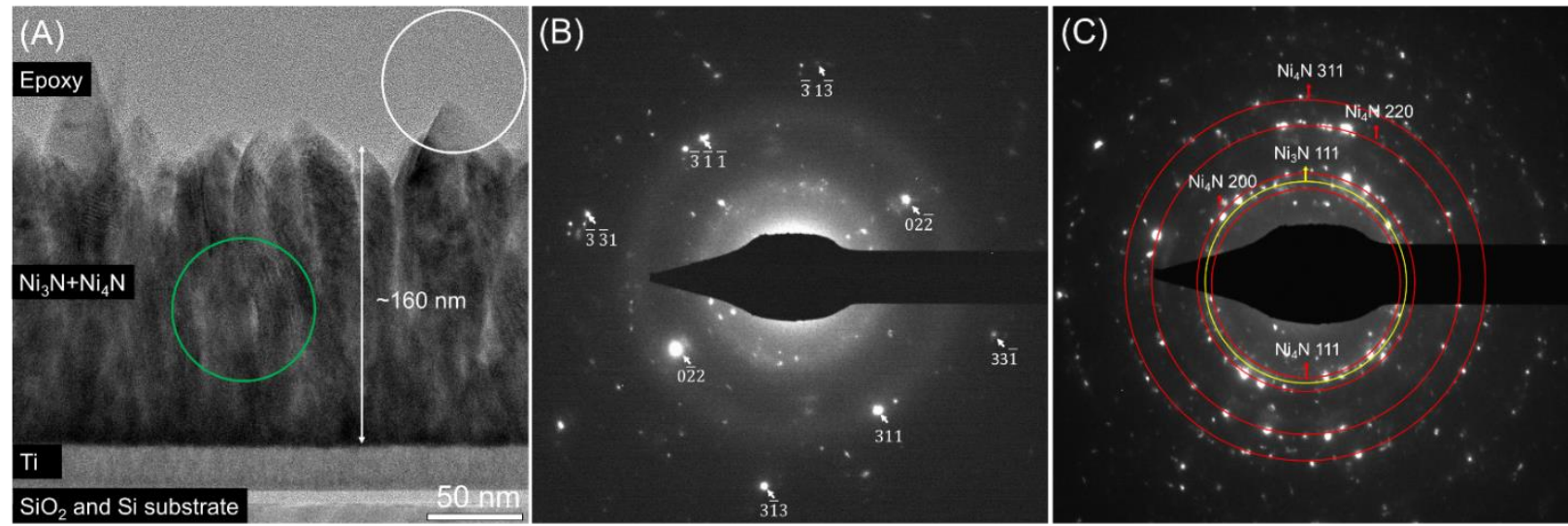

Figure 1. BF-TEM and SADP of as-prepared $\mathrm{Ni}_{\mathrm{x}} \mathrm{N}$ thin films with desired thickness of $\sim 160 \mathrm{~nm}$. (A) cross-sectional view, (B) SADP taken from white-circled region in (A) matching DP of $\mathrm{Ni}_{4} \mathrm{~N}$ from [233] zone axis, (C) SADP taken from green-circled region in (A) showing diffraction rings of $\mathrm{Ni}_{4} \mathrm{~N}_{\text {and }} \mathrm{Ni}_{3} \mathrm{~N}$.
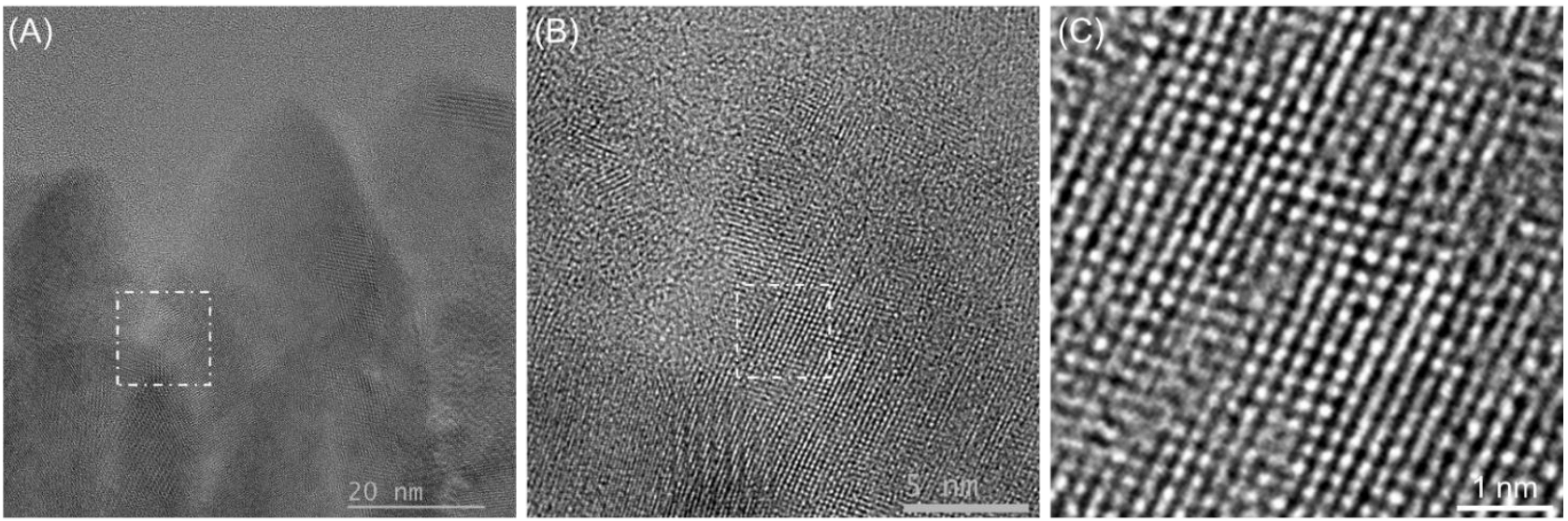

Figure 2. HR-TEM images of the $\mathrm{Ni}_{\mathrm{x}} \mathrm{N}$ thin film. (A) HR-TEM images of the thin film, (B) magnified image of the marked region in (A) showing lattice fringes. (C) higher magnification of marked box in (B).
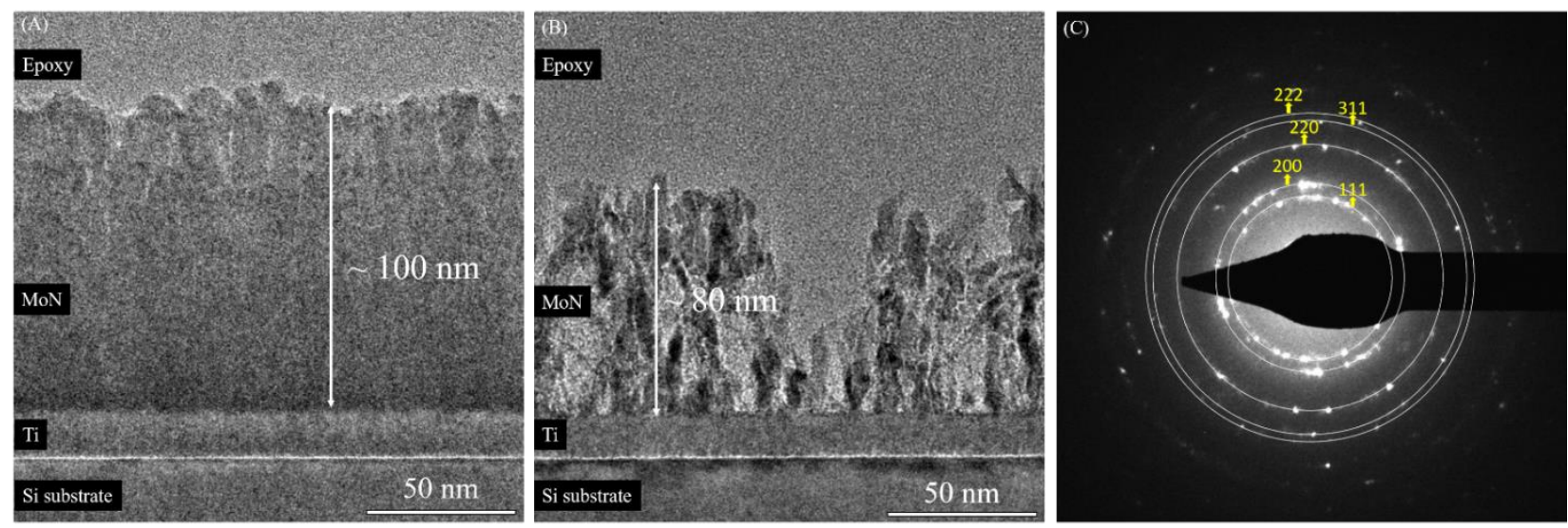

Figure 3. BF-TEM and SADP of $\mathrm{Mo}_{\mathrm{x}} \mathrm{N}$ thin films. (A) and (B) TEM images of as-deposited and after test $\mathrm{Mo}_{\mathrm{x}} \mathrm{N}$ thin film showing that the thickness of the film decreased from $100 \mathrm{~nm}$ to $80 \mathrm{~nm}$ with severe depressions (C) SADP of as-deposited $\mathrm{Mo}_{\mathrm{x}} \mathrm{N}$ thin film taken over its bulk region showing an FCC pattern consistent with the rocksalt MoN crystal structure both before and after test. 